\title{
Good Parameters for PSO in Optimizing Laying Hen Diet
}

\author{
Gusti Ahmad Fanshuri Alfarisy ${ }^{1}$, Wayan Firdaus Mahmudy ${ }^{2}$, Muhammad Halim Natsir ${ }^{3}$ \\ ${ }^{1,2}$ Faculty of Computer Science, Universitas Brawijaya, Indonesia \\ ${ }^{3}$ Faculty of Animal Husbandry, Universitas Brawijaya, Indonesia
}

\begin{tabular}{l}
\hline Article Info \\
\hline Article history: \\
Received Feb 11, 2018 \\
Revised May 12, 2018 \\
Accepted Jun 2, 2018 \\
\hline
\end{tabular}

Keyword:

Feed Formulation

Particle Swarm Optimization

Good Parameter

\begin{abstract}
Manual formulation of poultry diet by taking into account the fulfillment of all nutrients requirement with least cost is a difficult task. Particle Swarm Optimization (PSO) shows promising technique to solve this problem. However, there is a lack of studying a good parameter for PSO to solve feed formulation problem since PSO is sensitive to control parameter which depends on the problem. Therefore, this study investigates good swarm size, total iterations, acceleration coefficients, and inertia weight to produce a better formula. PSO with proposed good parameters is compared with other parameters. The obtained result shows that PSO with good parameters choice produces the highest fitness. Furthermore, good parameters of PSO can be used as a reference for a software developer and for further research to optimize poultry diet using PSO.
\end{abstract}

Copyright $\odot 2018$ Institute of Advanced Engineering and Science. All rights reserved.

\section{Corresponding Author:}

Wayan Firdaus Mahmudy,

Faculty of Computer Science,

Universitas Brawijaya,

Jln. Veteran No.8, Ketawanggede, Kecamatan Lowokwaru, Malang, Indonesia.

Email: wayanfm@ub.ac.id

\section{INTRODUCTION}

Feed that given on daily basis to poultry like laying hens is essential for growth, reproduction, and health. Feed should provide the nutrients that fulfill the nutrient's requirement for an animal. In poultry diets, the essential nutrients are protein, amino acids, carbohydrates, fats, minerals, and vitamins. These nutrients are important for producing meat and eggs [1]. Every class of animals with different stage or age require different nutrient requirements that needs different formula. When we take into account the cost of feed and several nutrient requirements, it becomes a complicated task to find the optimum formula that satisfy all nutrient requirements with least cost [2].

A feed intake by laying hens will affect the eggs production and price. It can be obtained only from a good formula which fulfills the nutrient requirements. Unfortunately, the highest cost production is in the feed approximately 65-70\% of all cost production. The feed and other cost have a positive correlation to the eggs price. If the producer can lower the cost with optimum feed's formula, it will become cost-saving for him and may decrease the eggs price [3].

In Formulating the optimum formula, several factors must be considered simultaneously like the availability of local resources, fluctuating prices, and proper nutrition. A number of manual formulation such as trial and error, simultaneous algebraic equations, pearson's square method have fail to produce optimum formula due to complexity when considering many nutrients and taking into account the feed's price. Another approach, stochastic approach, has been employed by previous researches such as, Chance Constrained Programming (CCP), Quadratic Programming (QP), and Risk Formulation (RP). CCP is nonlinear method that used for feed formulation but consuming time since trial and error method is used in each iterations. QP is not suitable on the large problem and RP is a complex method [4]. 
Meta-heuristic approach for stochastic optimization can be used to find optimal feed formulation [5]. It overcomes the lack of heuristic approach in the large search space [6]. It involving the objective function to evaluate the fitness of candidate solution and can be used to determine the direction of search trajectories for finding better candidate solution [7].

One of the meta-heuristic methods that can be employed to overcame the deficiency of those methods is Particle Swarm Optimization (PSO). PSO has shown a promising optimization method to solve a complex problem such as power system [8], electronic industry, wireless sensor network, feature selection [9], circuit design [10], multi-objective optimization [11], and determining neuron weights in fuzzy neural networks [12].

In previous studies conducted by Altun and Şahman [13], PSO is employed to formulate optimum feed on several animals such as cattle, sheep, and rabbits. This algorithm can handle the constraint of each feed and can find the optimum solution for complex nutritional needs with least cost. The result shows us that PSO is able to provide a better solution than linear programming methods and genetic algorithm. In the other hand, the model of mult-objective optimization based on PSO defined in Xu study [14]. However, their study does not investigate the good parameter for PSO.

When employing PSO, good choice for control parameter such as inertia weight, cognitive and social coefficient may enhance the performance of PSO. Furthermore, good parameter initialization depends on the problem and different problem may require a different choice of control parameters. The right parameter choice may lead particle to exploit or explore search trajectory to the optimum solution. While the wrong choice may aggravate the PSO ability for finding the global optimum solution [15]. The good swarm size and total iteration could affect PSO performance significantly. Therefore, it is important to choose good control parameters of PSO for a particular problem. Furthermore, the software developer can select the good parameter for their application.

In the feed mix problem, the complexity of search space depends on the choice of feed that has nutrient value, stage of laying hen, and fluctuating prices. When producer changes the choices, the feed composition based on the choice is also changed. Thus, it is important to choose good parameter based on several formulae rather than just one.

The objective of this study is to investigate the good swarm size, a number of iteration, acceleration coefficients, and inertia weight of PSO in optimizing laying hen diet. The experiment is based on five different formula that needs to be optimized. The obtained good parameters than compared to another parameter's value in PSO in order to find the optimum formula. Optimum means that the feed is fulfilling the nutrient requirements with least cost.

\section{RESEARCH METHOD} following:

The swarm intelligence approach and the application to optimize laying hen diet is discused in

\subsection{Particle swarm optimization}

Particle Swarm Optimization (PSO) gaining popularity since its emergence in 1995 by Eberhart and Kennedy [16] and inertia weight is added by Shi and Eberhart [17] to control the momentum of global best position and personal best position. PSO is an algorithm to find optimum solution that inspired from the population-based movement of swarm of fish and bird [18].

The first step is to generate initial swarm or population which each particle or individual (candidate solution) have their own velocity and position. Next step is to calculate the fitness function of each particle. Then save the best fitness value of each particle as Pbest (best position in a particle) and save the best of all particles as Gbest (best position of all particles). Then update the velocity and position of each particle with Equations (1) and (2). PBest of each particle is updated as well as gBest. This process continues until the terminate condition is satisfied. Finally, Gbest becomes the optimum solution among all the particles.

$$
\begin{aligned}
& P_{\text {velocity }}(i)=w \cdot P_{\text {velocity }}(i)+c_{1} \cdot r_{1}\left(P_{\text {pBest }}(i)-P_{\text {position }}(i)\right)+ \\
& c_{2} \cdot r_{2}\left(P_{\text {gBest }}-P_{\text {position }}(i)\right) \\
& P_{\text {position }}(i)=P_{\text {position }}(i)+P_{\text {velocity }}(i)
\end{aligned}
$$

Each particle represents the candidate solution which has velocity and position respectively. Velocity updated based on the best its own particle and the best of all particle. Therefore, the particle has attractiveness to personal best and global best position. 


\subsection{PSO Application to optimization of laying hen diet}

The value for each dimension in a particle is real value that must satisfy the hard constraint which is equal to $100 . P_{i}(t)$ denotes the particle $i$-th at $t$-iteration that contain a set of various types of feed $\left(\mathrm{x}_{\mathrm{i}}\right)$ with a specific percentage and $\mathrm{D}$ denotes the total type of feed which also denotes the dimension of particles. The particle in particular iteration can be expressed in following :

$$
P_{i}(t)=\left\{x_{i, 1}, x_{i, 2}, x_{i, 3}, \ldots, x_{i, D}\right\}
$$

On the condition that total number of $x_{i}$ in the set $P_{i}(t)$ is equal to 100 . Thus, particle representation of $i$-th particle for feed formulation is shown in Figure 2 and the example of particle representation which have $\mathrm{D}=3$ is shown in Figure 1 .

During particle movement, total percentage may not satisfy $100 \%$. Thus, Equation (3) is used to adjust the current total percentage to $100 \%$.

\begin{tabular}{ccccccc}
\hline Feed $_{1}$ & Feed $_{2}$ & $\ldots$ & Feed $_{\mathrm{j}}$ & $\ldots$ & Feed $_{\mathrm{D}}$ & Total percentage \\
\hline$x_{i, 1}$ & $x_{i, 2}$ & $\ldots$ & $x_{i, j}$ & $\ldots$ & $x_{i, D}$ & $\sum_{j=1}^{D} x_{i, j}=100$ \\
& & & & & & \\
\hline
\end{tabular}

Figure 1. Particle representation

\begin{tabular}{cccc}
\hline $\mathrm{p}_{1}($ corn $)$ & $\mathrm{p}_{2}($ barn $)$ & $\mathrm{p}_{3}$ (concentrate) & Total Percentage \\
\hline 35,000 & 50,000 & 15,000 & 100 \\
\hline
\end{tabular}

Figure 2. Example of particle representation

$$
x_{i, j}=\operatorname{round}\left(\frac{x_{i, j}}{\sum_{j=1}^{D} x_{i, j}} \times 100 \%\right)
$$

For example in $\mathrm{t}$-th iteration of particle $\mathrm{i}$, the particle have the following values:

\begin{tabular}{cccc}
\hline Corn & Barn & Concentrate & Total Percentage \\
\hline 54,897 & 30,564 & 34,539 & $120 \%$ \\
\hline
\end{tabular}

Since total percentage is not equal to $100 \%$, this particle need readjustment. An example of readjustment process of the particle can be seen in following :

$$
\begin{aligned}
& x_{i, 1}=\frac{54,897}{120} \times 100 \%=45,8333=45,7475 \\
& x_{i, 2}=\frac{30,564}{120} \times 100 \%=25,47 \\
& x_{i, 3}=\frac{34,539}{120} \times 100 \%=29,6158333
\end{aligned}
$$

\begin{tabular}{cccc}
\hline Corn & Barn & Kosentrat & Total Percentage \\
\hline 45,7475 & 25,47 & 29,6158333 & $100 \%$ \\
\hline
\end{tabular}

Measuring the accuracy of nutrients of particle that fulfill the nutrient requirement is using the distance or penalty between nutrient value (see Appendix for more detail) and actual nutrient requirement. The penalty must be near zero which indicate the formulation is feasible for laying hens diets. Long distance or higher value of penalty represent bad particle as well as cost or price. The more distance of cost, the more particle is not optimum. Therefore the objective function or fitness function in PSO can be described as 1 divided by the sum of penalty and cost that should be maximized as shown in Equation (4).

$$
\operatorname{fitness}\left(P_{i}\right)=\frac{1}{p N u \operatorname{trient}\left(P_{i}\right)+p \operatorname{Cost}\left(P_{i}\right)}
$$


Specifically, in order to estimate the distance to produce a good fitness function, the analysis of laying hens nutrient requirements is necessary. As shown in Table 5, the nutrient requirements are different on each layer and each nutrient has different limit that can be categorized as the minimum, maximum, and range of the sufficient nutrient [19]-[24]. Thus, we need a function that accommodate nutrient penalty of each feed which is shown in Equations (5), (6), (7), and (8). nutrient ${ }_{a}\left(x_{i, j}\right)$ denotes the nutrient $a$ value on $\mathrm{j}$-th position or feed on i-th particle, $k$ denotes the amount of nutrient requirement of laying hens on particular layer and nutrient. $f_{\text {min }}\left(P_{i}, a\right), f_{\text {max }}\left(P_{i}, a\right)$, and $f_{\text {range }}\left(P_{i}\right.$, a) particularly denote a function which produces a penalty as an output from the requirements of minimum nutrient, maximum nutrient, and range between minimum and maximum value of the nutrient.

Equation (9) is the summation of all penalties of all nutrients in a particle based on the nutrient requirement. Each nutrient has min and max property that show a minimum and maximum value of the nutrient. If min and max property are greater than zero than it is indicated that nutrient has range requirement between min and max value. If the max property value is greater than zero and min property value is equal or less than zero, then it is in indicating that nutrient has minimum requirement. Otherwise, it has a minimum requirement.

The total price of a particle need to be normalized in order to make the price range is close to nutrient value. Thus, the cost function can be defined in Equation $(10)$ where $\operatorname{totalCost}(P)$ is the total price in a particle. $\max \operatorname{Cost}(P)$ denotes the maximum price while $\min \operatorname{Cost}(P)$ denotes the minimum price of all feeds.

However, the position may have negative value during iteration. To overcome this issue, we set the fitness function value to negative. It indicates that the particle can't be a solution to feed formulation problem. During movement, the particles will learn from their cognitive and social experience towards positive fitness value with positive positions.

Table 1. Laying Hens Nutrient Requirements

\begin{tabular}{|c|c|c|c|c|c|c|c|c|c|}
\hline No & Nutrient & Unit & & $\begin{array}{c}\text { Layer Pre } \\
\text { Starter (1 - } 4 \\
\text { Weeks) }\end{array}$ & $\begin{array}{c}\text { Layer } \\
\text { Starter (5 - } \\
10 \text { Weeks) }\end{array}$ & $\begin{array}{c}\text { Layer } \\
\text { Grower } \\
(11-16 \\
\text { Weeks })\end{array}$ & $\begin{array}{c}\text { Pre Layer } \\
(17-18 \\
\text { Weeks })\end{array}$ & $\begin{array}{l}\text { Layer } \\
(19-50 \\
\text { Weeks })\end{array}$ & $\begin{array}{c}\text { Layer Post } \\
\text { Peak ( > 50 } \\
\text { Weeks ) }\end{array}$ \\
\hline 1 & Crude Protein $(\mathrm{CP})$ & $\%$ & Min & 20.00 & 19.00 & 15.50 & 16.00 & 16.50 & 16.00 \\
\hline 2 & Lysin (Lys) & $\%$ & Min & 1.00 & 0.90 & 0.70 & 0.75 & 0.80 & 0.75 \\
\hline 3 & $\begin{array}{l}\text { Methionine (Met) } \\
\text { Methionine + }\end{array}$ & $\%$ & Min & 0.50 & 0.40 & 0.30 & 0.35 & 0.40 & 0.35 \\
\hline 4 & Cystine (Met+Cys) & $\%$ & Min & 0.80 & 0.70 & 0.60 & 0.63 & 0.67 & 0.65 \\
\hline 5 & Tryptophan (Tryp) & $\%$ & Min & 0.20 & 0.18 & 0.17 & 0.17 & 0.18 & 0.17 \\
\hline 6 & Threonine (Thre) & $\%$ & Min & 0.75 & 0.65 & 0.50 & 0.52 & 0.55 & 0.50 \\
\hline 7 & Crude Fat (F) & $\%$ & Min & 3.00 & 3.00 & 3.00 & 3.00 & 3.00 & 3.00 \\
\hline 8 & Crude Fiber (CF) & $\%$ & $\operatorname{Max}$ & 6.00 & 7.00 & 8.00 & 8.00 & $\begin{array}{r}7.00 \\
3.25-\end{array}$ & 8.00 \\
\hline 9 & $\begin{array}{l}\text { Calcium }(\mathrm{Ca}) \\
\text { Total Phosphorus }\end{array}$ & $\%$ & Range & $0.80-1.20$ & $0.80-1.20$ & $0.80-1.20$ & $2.00-2.70$ & 4.25 & $3.50-4.50$ \\
\hline 10 & $\begin{array}{l}(\mathrm{P}) \\
\text { Metabolizable }\end{array}$ & $\%$ & Min & 0.60 & 0.55 & 0.46 & 0.50 & 0.55 & 0.50 \\
\hline 11 & Energy (ME) & $\mathrm{Kkal} / \mathrm{Kg}$ & Min & 2900.00 & 2800.00 & 2700.00 & 2700.00 & 2700.00 & 2650.00 \\
\hline
\end{tabular}

Let assume that we use 3 nutrient, first nutrient using the maximum function, the second nutrient using the minimum function, and the third nutrient using range function. Then the fitness function can be defined in Equation (9). Nutrients that used in this study are same with the nutrient requirements in Table 1 and example of feed nutrients is shown in Table 2. Therefore, the fitness function can be defined in Equation (10).

Table 2. Example of Feed Nutrients

\begin{tabular}{rlrrrrr}
\hline No & \multicolumn{1}{c}{ Nutrient } & Unit & \multicolumn{1}{c}{ Bran } & Yellow Corn & Soybeans & Coconut Meal \\
\hline 1 & Crude Protein (CP) & $\%$ & 10.2 & 8.54 & 38 & 18.5 \\
2 & Lysin (Lys) & $\%$ & 0.71 & 0.2 & 2.4 & 0.64 \\
\hline
\end{tabular}




\begin{tabular}{rlrrrrr}
\hline No & \multicolumn{1}{c}{ Nutrient } & Unit & \multicolumn{1}{c}{ Bran } & Yellow Corn & Soybeans & Coconut Meal \\
\hline 3 & Methionine (Met) & $\%$ & 0.27 & 0.18 & 0.51 & 0.29 \\
& Methionine + Cystine & $\%$ & 0.64 & 0.36 & 1.15 & 0.59 \\
4 & (Met+Cys) & $\%$ & 0.09 & 0.1 & 0.55 & 0.2 \\
5 & Tryptophan (Tryp) & $\%$ & 0.57 & 0.4 & 1.5 & 0.65 \\
6 & Threonine (Thre) & $\%$ & 7 & 2.61 & 18 & 2.5 \\
7 & Crude Fat (F) & $\%$ & 3 & 0.02 & 5 & 15 \\
8 & Crude Fiber (CF) & $\%$ & 0.04 & 0.02 & 0.25 & 0.2 \\
9 & Calcium (Ca) & $\%$ & 0.16 & 0.1 & 0.25 & 0.57 \\
10 & Total Phosphorus (P) & $\%$ & & 3370 & 2860 & 2200 \\
& Metabolizable Energy & Kkal/Kg & 2860 & 3700 & 5000 & 4200 \\
11 & (ME) & Rupiah/Kg & 3000 & & & \\
12 & Cost & & & & & \\
\end{tabular}

$$
\begin{aligned}
& \text { totalNutrient }_{a}\left(P_{i}\right)=\sum_{j=1}^{D} \frac{x_{i, j}}{100} \cdot \text { nutrient }_{a}\left(x_{i, j}\right) \\
& f_{\text {min }}\left(P_{i}, a\right)=\left\{\begin{aligned}
0, \text { totalNutrient }_{a}\left(P_{i}\right) & \geq k \\
k-\text { totalNutrient }_{a}\left(P_{i}\right), \text { totalNutrient }_{a}\left(P_{i}\right) & <k
\end{aligned}\right. \\
& f_{\text {max }}\left(P_{i}, a\right)=\left\{\begin{aligned}
\text { totalNutrient }_{a}\left(P_{i}\right)-k, \text { totalNutrient }_{a}\left(P_{i}\right) & >k \\
0, \text { totalNutrient }_{a}\left(P_{i}\right) & \leq k
\end{aligned}\right.
\end{aligned}
$$

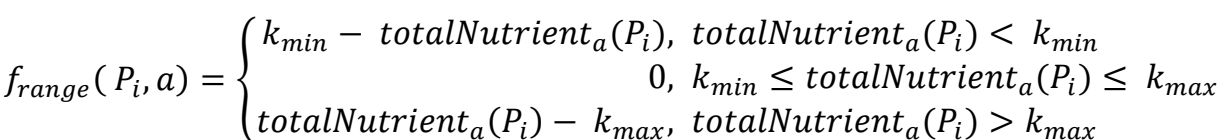

$$
\begin{aligned}
& \operatorname{pNutrient}\left(P_{i}\right)=\sum_{j=1}^{N}\left\{\begin{aligned}
f_{\text {range }}\left(P_{i}, j\right), & P_{i, j, \min }>0 \wedge P_{i, j, \max }>0 \\
f_{\text {max }}\left(P_{i}, j\right), & P_{i, j, \min } \leq 0 \\
f_{\text {min }}\left(P_{i}, j\right), & P_{i, j, \max } \leq 0
\end{aligned}\right. \\
& p \operatorname{Cost}(P)=\frac{\operatorname{total\operatorname {Cost}}(P)-100 \cdot \min \operatorname{Cost}(P)}{100 \cdot \max \operatorname{Cost}(P)-100 \cdot \min \operatorname{Cost}(P)}
\end{aligned}
$$

\subsection{Experimental setup}

In this study, we perform 4 testing scenario that aim to get insight about good swarm size, the good number of iteration, good acceleration coefficients, good inertia weight and performance of good parameters in PSO for feed formulation in laying hen diets. First control parameter choices are 0.6 for inertia weight coefficient and 1.7 for both acceleration coefficients. All experiment is using grower phase of laying hen.

In the first scenario, we experiment with 5 different formula that can be seen in Table 3 to find a good swarm size. For all formula, we run PSO with different swarm size that has ranged between 10 and 100 by 10 with 10,000 iterations. This scenario designed to figure out the effect of the different combination of feed towards best swarm size for formulating optimum diet.

In the second scenario, the same feed combination from scenario 1 is used which using different total iteration that has ranged between 1,000 to 10,000 by 1,000 and best swarm size is used that derived from scenario 1. This scenario is intended to figure out the best number of iteration towards different feed combinations.

In third scenario, we tuning cognitive and social coefficients to get the best control parameter for PSO in case of feed formulation problem. The value between 0.1 to 2.0 and increased by 0.1 for both coefficient is tested. We use the good swarm size and good number of iterations derived from scenario 1 and 2 .

In the fourth scenario, we tuning different value of constant inertia weight for all different formula. The value between 0.1 to 0.9 by 0.1 . We use the good swarm size, iteration, and acceleration coefficients derived from scenario 1,2 , and 3 .

In the fifth scenario, we use the good swarm size derived from scenario 1, good total iterations derived from scenario 2, good acceleration coefficients derived from scenario 3, and good inertia weight derived from scenario 4 . We test these parameters to other parameter settings such as linearly decreasing 
inertia weight with $\max =0.9$ and $\min =0.4$ since it is considered mostly used in PSO applications [25] and $\mathrm{w}=0.729, \mathrm{c} 1=1.494, \mathrm{c} 2=1.494$ [26] using formulae in Table 4. Since PSO is stochastic optimization that produce fluctuating results, we run PSO ten times for fair analysis.

Table 3. Test Formulae for Good Parameters

\begin{tabular}{ll}
\hline Formula & Feed \\
\hline $5 \mathrm{~A}$ & $3,4,5,25,26$ \\
$6 \mathrm{~A}$ & $2,4,10,17,24,26$ \\
$8 \mathrm{~A}$ & $1,3,8,10,11,15,18,21$ \\
$11 \mathrm{~A}$ & $2,4,8,13,15,16,19,20,21,22,26$ \\
$15 \mathrm{~A}$ & $0,2,5,6,7,8,9,10,19,25,22,23,24,26,27$ \\
\hline
\end{tabular}

Table 4. Test Formulae for Comparison

\begin{tabular}{ll}
\hline Formula & Feed \\
\hline 11B & $0,1,3,11,13,16,20,22,23,26,30$ \\
12B & $0,2,3,8,10,15,17,19,20,21,24,26$ \\
13B & $1,3,5,8,9,10,13,17,19,20,24,27,30$ \\
\hline
\end{tabular}

\section{RESULTS AND DISCUSSION}

All the testing scenarios are implemented using Scala programming language that combines objectoriented and functional paradigm. The results for each scenario is discussed in the following section:

\subsection{Good swarm size}

The effect of an increase in swarm size for all formula is shown in Figure 3. It is shown that each formula requires different minimum swarm size to found the optimum formula. Formula $5 \mathrm{~A}$ and $6 \mathrm{~A}$ need at least 20 swarm size, formula $8 \mathrm{~A}$ neet at least $50 \mathrm{swarm}$ size, formula $11 \mathrm{~A}$ need at least $30 \mathrm{swarm}$ size, and formula $15 \mathrm{~A}$ need at least 180 swarm size. In $15 \mathrm{~A}$, increasing swarm size above 180 could not give any significant improvement for the average fitness value.

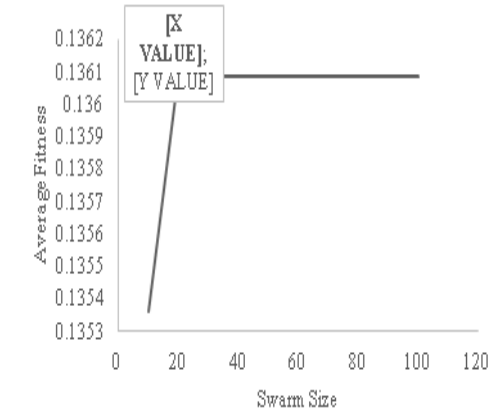

(a)

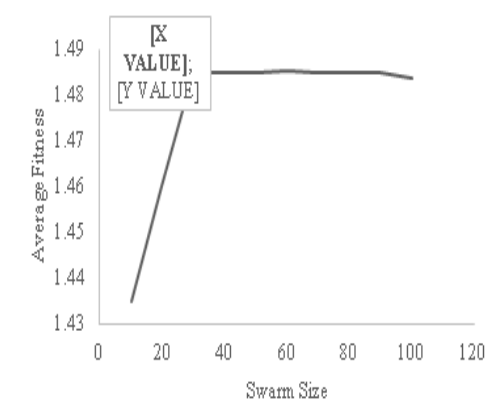

(d)

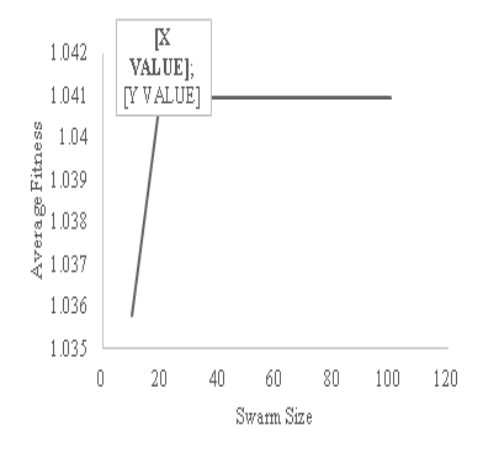

(b)

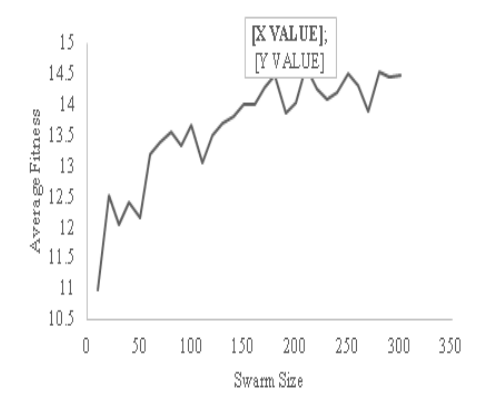

(e)

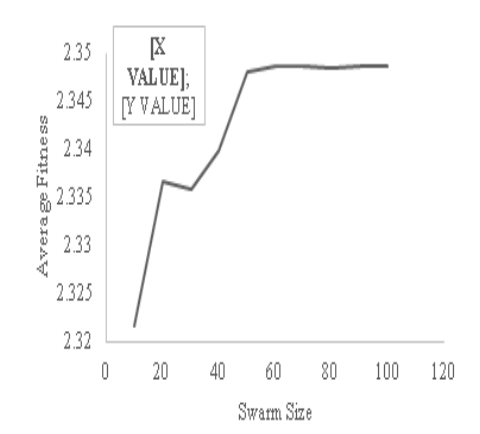

(c)

Figure 3. Effect of swarm size to average fitness on formula: (a) 5A, (b) 6A, (c) 8A, (d) 11A, and (e) 15A 
Each minimum swarm size gives us insight that the number of feeds in each formula is not associated with the minimum swarm size. With 5 and 6 different feed combination, they require minimum 20 swarm size and the minimum value is increased with 8 different combinations that need at least 50 swarm size. However, when the number of feeds is increased to 11 different combinations, it requires less swarm size than $8 \mathrm{~A}$ which at least 30 swarm size. Thus, the complexity of search space is not associated with the number of feeds

Then, It is very difficult to find minimum swarm size for every combination of feeds. Since the number of combination is very large and the cost of feed is fluctuating that increase the combination complexity through time (the cost always change). However, with a small sample of experimentation, we can choose the highest swarm size to be the good parameter. The highest swarm size can make particles converge on all formula. It is highly likely that this good parameter is not good for another formula outside of the sample. Therefore, we propose to add additional swarm size for the highest swarm size found in a small sample. In this case, the highest swarm size is 180 , then the good swarm size would be $180+\mathrm{X}$ which $\mathrm{X}$ is the arbitrary number of swarm size that possibly can help particles converge in a better solution.

For the next experiment, we choose arbitrary value $X=50$ and then the good swarm size $=230$. The determination of this value is another problem that is not discussed in this paper.

\subsection{Good number of iteration}

For formula $5 \mathrm{~A}$ and $6 \mathrm{~A}, 1,000$ iterations are adequate to make particle to converge as shown in Figure 4. By increasing the dimension, $8 \mathrm{~A}$ require minimum iterations of 4,000, 11A require minimum iterations of 5,000, while $15 \mathrm{~A}$ require minimum iterations of 14,000. Each formula shows different total iterations. With a small sample of 5 different formula, the highest number of iterations is found in formula 11A. If this value is used as a good number of iterations it can make particle converge in all sample formula. Thus, we propose an additional number of iterations in accounting feed combination outside of sample. The good number of iterations should be $14,000+\mathrm{Y}$ which $\mathrm{Y}$ is the arbitrary number of iterations.

For the experiment of acceleration coefficient, we choose arbitrary $\mathrm{Y}=5,000$, good number of iterations $=$ 19,000. This determination is another problem that is not discussed in this paper.

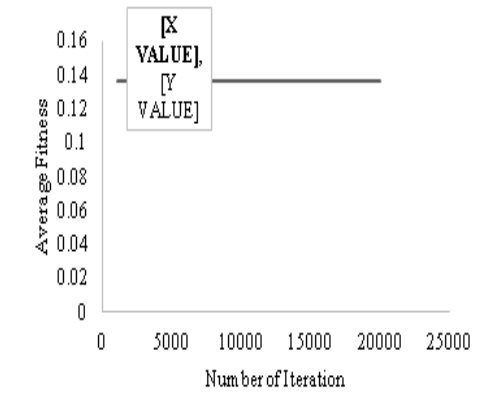

(a)

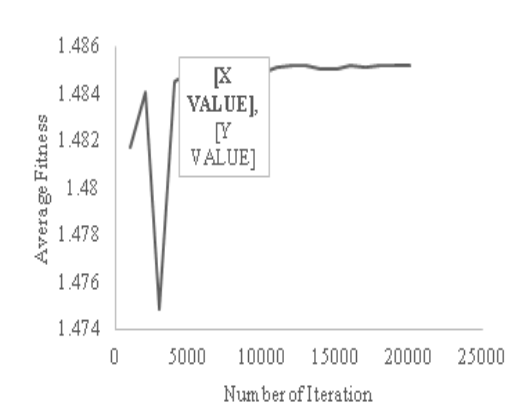

(d)

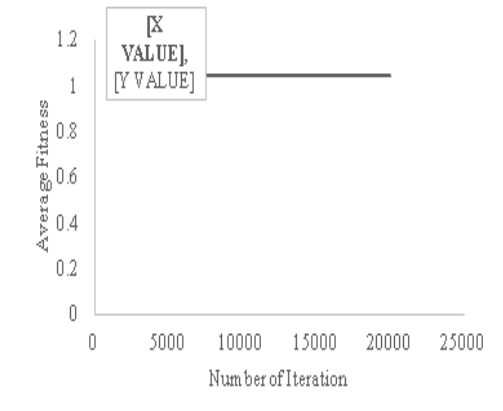

(b)

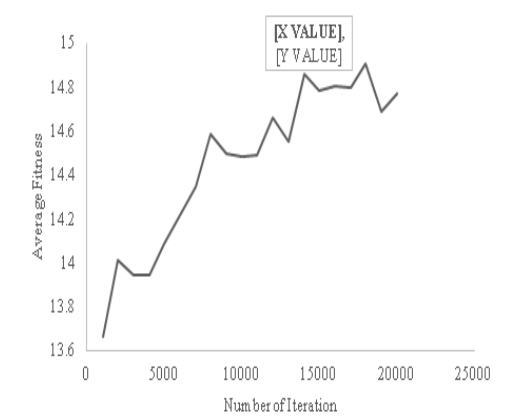

(e)

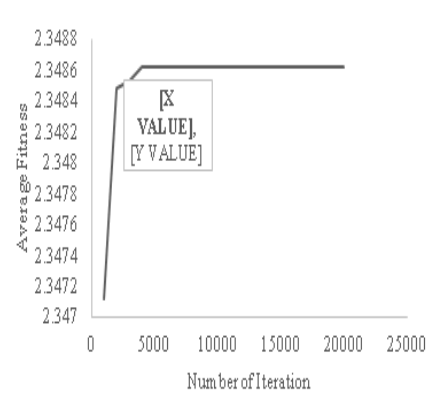

(c)

Figure 4. Effect of number of iterations to average fitness on formula: (a) 5A, (b) 6A, (c) $8 \mathrm{~A}$, (d) $11 \mathrm{~A}$, and (e) $15 \mathrm{~A}$ 


\subsection{Good acceleration coefficients}

The effect of acceleration coefficients to average fitness value is shown in Figure 5. The increase of social coefficient gives significant improvement to average fitness for all formulae. While using small social coefficient with high cognitive coefficient can't improve average fitness which leads to bad choices. The social coefficient above 1.0 with a small value of the cognitive coefficient is enough to produce optimum formula. However, with this small sample of experimentation, it is safe to choose a high value for both acceleration coefficient. Thus, in this study, we choose cognitive coefficient of 2.0 and social coefficient of 2.0 .

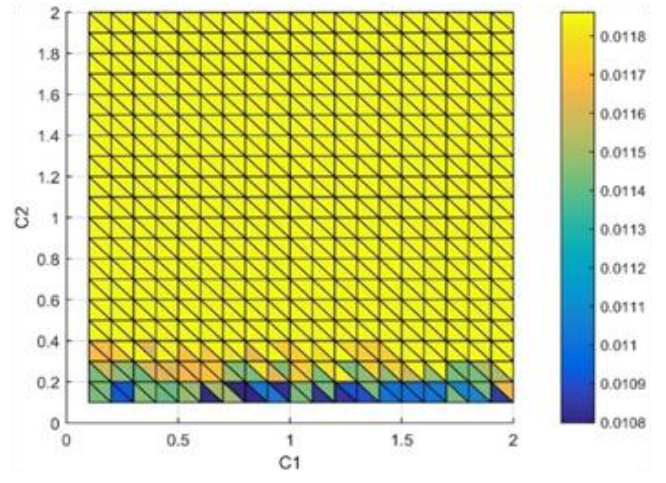

(a)

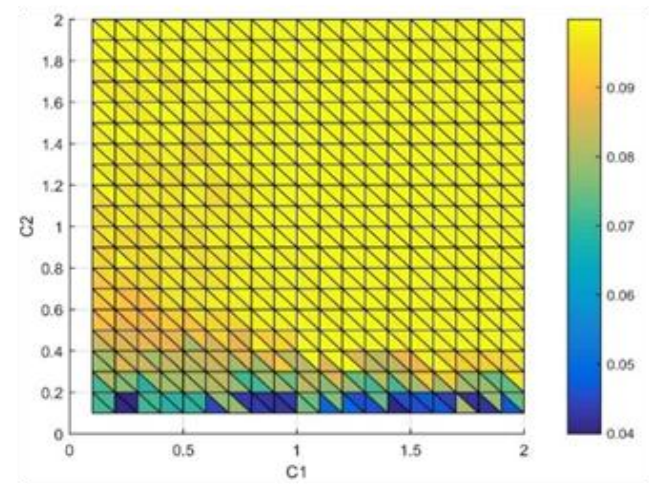

(c)

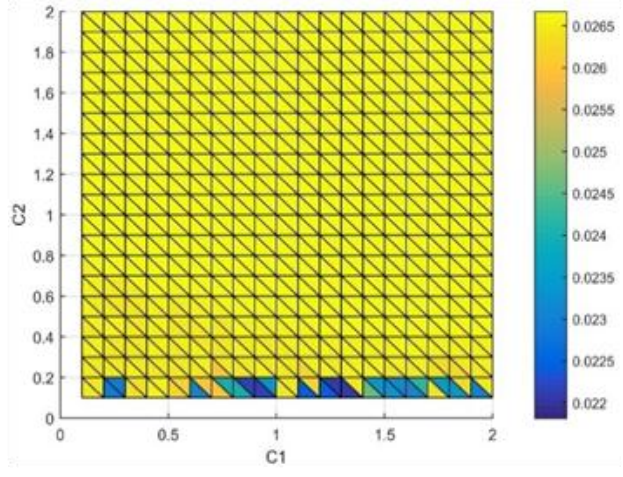

(b)

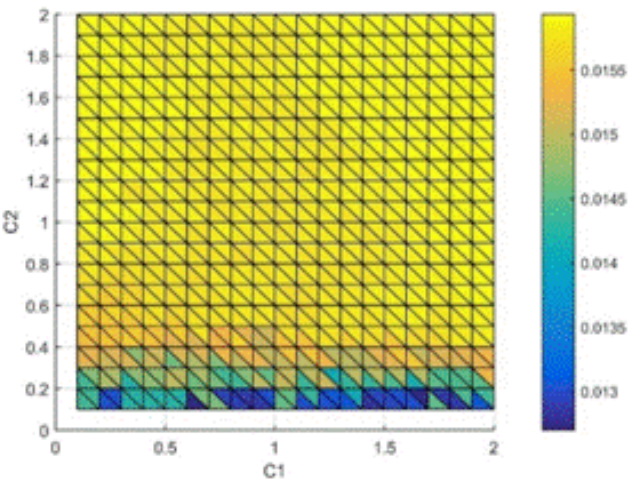

(d)

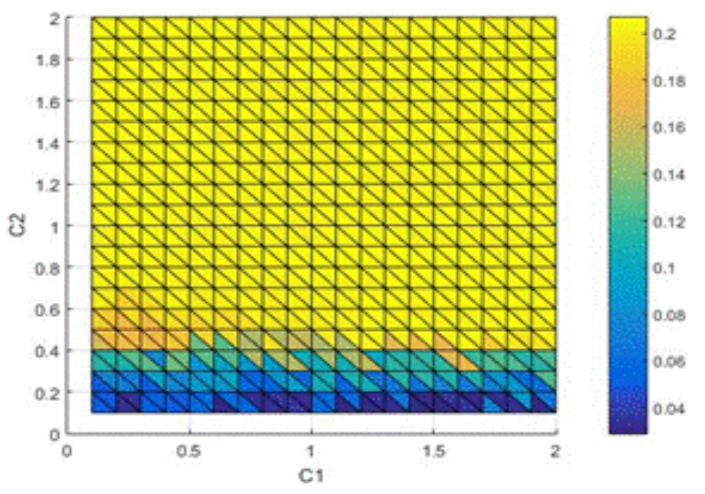

(e)

Figure 5. Effect of acceleration coefficients to average fitness on formula: (a) 5A, (b) 6A, (c) 8A, (d) 11A, and (e) $15 \mathrm{~A}$ 


\subsection{Good inertia weight}

The effect of inertia weight value to average fitness is shown in Figure 6. In all formula, except formula $8 \mathrm{~A}$, a high value of inertia weight decrease the average fitness. In formula $5 \mathrm{~A}$ and $6 \mathrm{~A}$, inertia weight of 0.1 to 0.7 does not increase or decrease average fitness significantly and it is considered as a good parameter in $5 \mathrm{~A}$ and $6 \mathrm{~A}$. While in $8 \mathrm{~A}$, inertia weight of 0.1 to 0.9 does not decrease the average fitness and considered as a safe value to choose as a good parameter. In $11 \mathrm{~A}$, inertia weight of 0.1 to 0.6 is a safe choice to choose. In formula $5 \mathrm{~A}, 6 \mathrm{~A}, 8 \mathrm{~A}$, and $11 \mathrm{~A}$, the increment of inertia weight in safe value does not improve significantly to average fitness. However, in $15 \mathrm{~A}$, average fitness gradually increased from 0.1 to 0.7 and decreased significantly above 0.7 .

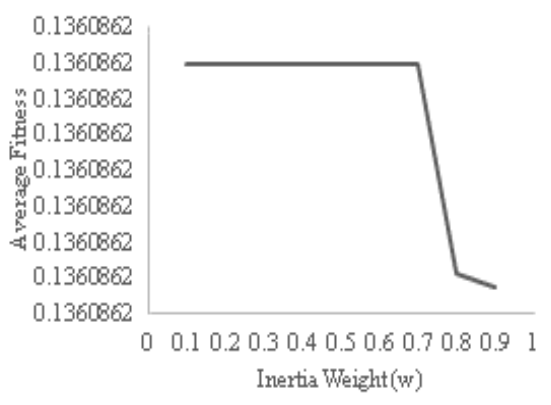

(a)

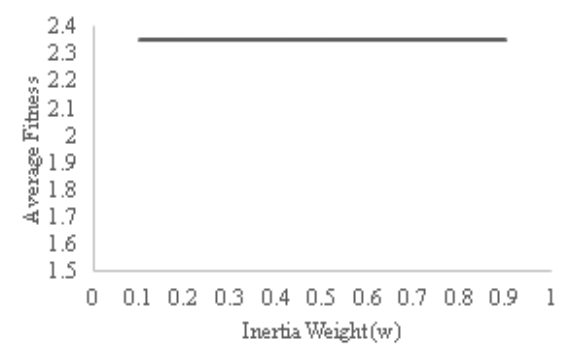

(c)

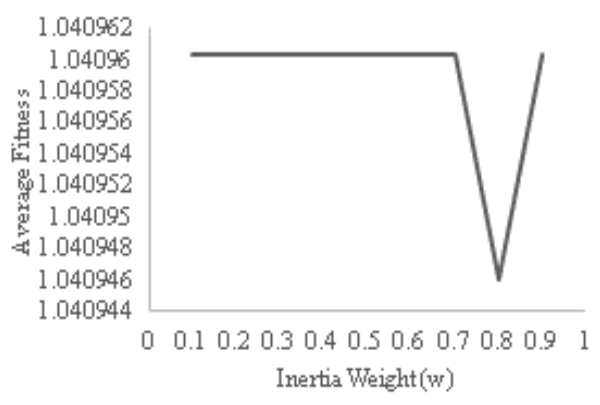

(b)

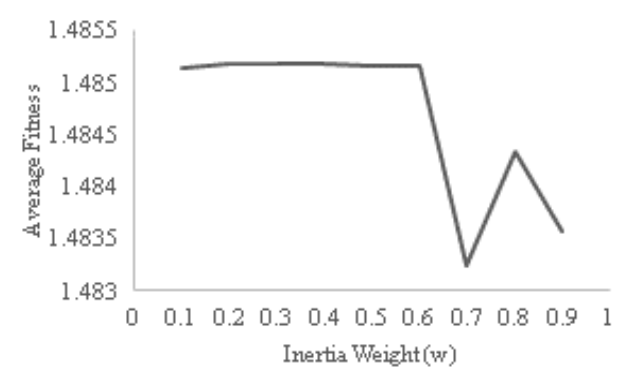

(d)

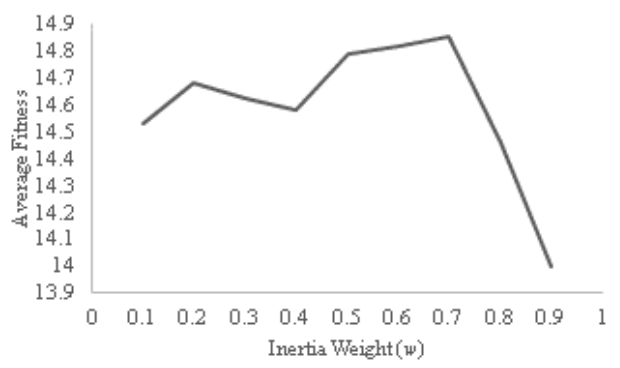

(e)

Figure 6. Effect of inertia weight to average fitness on formula: (a) $5 \mathrm{~A}$, (b) $6 \mathrm{~A}$, (c) $8 \mathrm{~A}$, (d) $11 \mathrm{~A}$, (e) and $15 \mathrm{~A}$

The simulation results show us that a good parameter of inertia weight differs from formula to another formula. The choice should be below 0.7 since it is the safe choice to choose that not decreasing the average fitness that found in formula $5 \mathrm{~A}, 6 \mathrm{~A}, 8 \mathrm{~A}$, and $15 \mathrm{~A}$. However, 0.7 is considered to be a bad choice because it will decrease the average fitness in formula 11A. With a small sample, the inertia weight in $[0.5,0.6]$ should be chosen as a good choice parameter since it is safe to choose in the small sample of experimentation. 


\subsection{Comparison results}

The good parameter choices of PSO which are swarm size $=230$, iterations $=19,000, \mathrm{c} 1=2,0$, $\mathrm{c} 2=2,0$, and $\mathrm{w}=0,6$ is compared to other PSO parameters. The comparison is simulated with the same swarm size and iterations in order to know how acceleration coefficients and inertia weight could affect the PSO performance and for a fair comparison. As shown in Table 5, all formulae produced by PSO-1 have the highest fitness value than PSO-2 and PSO-3. The inertia weight of PSO-2 and PSO-3 may reduce the average fitness since as found in inertia weight experimentation; the inertia weight above 0.7 could reduce the average fitness. However, PSO-3 is more stable than PSO-1 and PSO-2 as shown in the lowest standard deviation that found in $11 \mathrm{~A}$ and $13 \mathrm{~A}$. The simulation results show us that good parameter choice could improve the fitness or solution quality rather than just pick some swarm size, a number of iteration, and control parameter recommendation. This parameter can be used as a reference for PSO to solve poultry diet formulation problem.

Table 5. The comparison results of PSO with good parameter (PSO-1), PSO with linear decreasing inertia weight (PSO-2), and PSO with proposed parameter [26] (PSO-3)

\begin{tabular}{ccccccc}
\hline Formula & \multicolumn{2}{c}{ PSO-1 } & \multicolumn{2}{c}{ PSO-2 } & \multicolumn{2}{c}{ PSO-3 } \\
& Average Fitness & $\begin{array}{c}\text { Standard } \\
\text { Deviation }\end{array}$ & Average Fitness & $\begin{array}{c}\text { Standard } \\
\text { Deviation }\end{array}$ & Average Fitness & $\begin{array}{c}\text { Standard } \\
\text { Deviation }\end{array}$ \\
\hline 11A & 3.701377131 & 0.101223253 & 3.691529062 & 0.079904612 & 3.697482264 & 0.071724442 \\
$12 \mathrm{~A}$ & 7.287655999 & 0.063370121 & 7.2825648 & 0.054083732 & 7.285043867 & 0.088006539 \\
$13 \mathrm{~A}$ & 6.707823326 & 0.512793285 & 6.69813167 & 0.474649413 & 6.533627663 & 0.435799354 \\
\hline
\end{tabular}

\subsection{Formulation result}

This section presents the formulation result after all good parameter were obtained. Ten different ingredients were selected and formulated by PSO in grower phase. The composition of each ingredient and the amount of each nutrient are shown in Table 6 and 7 respectively. In Table 6, not all ingredients are used which PSO can selectively determine precise composition. While in Table 7, all nutrient requirements are satisfied. This simulation shows that PSO as promising algorithm to solve feed formulation problem, particularly in laying hens.

Table 5. Ingredients Composition and Cost

\begin{tabular}{lll}
\hline Ingredient & Compositior & Cost / Kg. \\
\hline Corn Bran & $24.166 \%$ & IDR 966.64 \\
Wheat & $0 \%$ & IDR 0 \\
Menir & $15.118 \%$ & IDR 907.08 \\
Pollard & $7.531 \%$ & IDR 173.213 \\
Cotton Seed & $4.553 \%$ & IDR 113.825 \\
Soybean Mei & $5.369 \%$ & IDR 161.07 \\
Foka & $42.428 \%$ & IDR 848.56 \\
MBM & $0.146 \%$ & IDR 7.3 \\
Blood Flour & $0.333 \%$ & IDR 16.65 \\
Bone Flour & $0.356 \%$ & IDR 21.36 \\
\multicolumn{2}{c}{ TOTAL } & IDR 3,215.698 \\
\hline
\end{tabular}

Table 6. Nutrient Penalty

\begin{tabular}{llll}
\hline Nutrient & Amount & Requirement & Description \\
\hline Met & 0.3 & Min. 0.30 & Satisfied \\
P & 0.46 & Min. 0.46 & Satisfied \\
Lys & 0.7 & Min. 0.70 & Satisfied \\
CF & 0.0 & Max. 8.00 & Satisfied \\
CP & 15.5 & Min. 15.50 & Satisfied \\
Thre & 0.5 & Min. 0.50 & Satisfied \\
Tryp & 0.17 & Min. 0.17 & Satisfied \\
Ca & 0.8 & $0.80-1.20$ & Satisfied \\
Met+Cys & 0.6 & Min. 0.60 & Satisfied \\
Nutrient & Amount & Requirement & Description \\
F & 3.0 & Min. 3.00 & Satisfied \\
EM & 2,700 & Min. 2,700 & Satisfied \\
\hline
\end{tabular}




\section{CONCLUSION}

This study presents the selection of PSO parameters to produce a better solution of laying hen diet. According to the experimental results, the choices of feed ingredients need different minimum swarm size and different total iterations. It shows us that the search space formed by the choices of feed ingredients that have nutrient value and cost property. It is become a hard task to find minimum swarm size and iteration for each combination. However, with a small sample of experimentation, the minimum swarm size and iteration should be above 180 and 14,000 respectively. In the other hand, acceleration coefficients require a high value to produce an optimum and stable formula. The cognitive coefficient of 2,0 and the social coefficient of 2,0 became the good choice to choose since it is a safe parameter to produce a better formula. While high value of inertia weight would reduce the fitness. Thus, the constant inertia weight between 0,5 and 0,6 should be chosen as good parameters.

Since the best parameter is different for each formula, the adaptive technique for inertia weight or swarm size can be beneficial for PSO to produce a better solution. Furthermore, multi-swarm with different parameter also advantageous to handle different combination and to avoid local optima in the complex multimodal problem.

\section{REFERENCES}

[1] National Research Council, Nutrient Requeriments of Poultry. Washington: National Academy Press, 1994.

[2] P. Saxena, "Optimization techniques for animal diet formulation," 2011. [Online]. Available: www.Gate2Biotech.com. [Accessed: 17-Oct-2016].

[3] O. M. Bamiro and A. M. Shittu, "Vertical integration and cost behavior in poultry industry in Ogun and Oyo states of Nigeria," Agribusiness, vol. 25, no. 1, pp. 1-15, 2009.

[4] R. A. Rahman, C. Ang, and R. Ramli, "Investigating Feed Mix Problem Approaches: An Overview and Potential Solution," World Academy of Science, Engineering and Technology, vol. 46, no. 10, pp. 424-432, 2010

[5] V. N. Wijayaningrum, W. F. Mahmudy, and M. H. Natsir, "OLD - Optimization of Poultry Feed Composition using Hybrid Adaptive Genetic Algorithm and Simulated Annealing," Journal of Telecommunication, Electronic and Computer Engineering, vol. 9, no. 2, pp. 1-5, 2017.

[6] W. F. Mahmudy, "Optimization of Part Type Selection and Machine Loading Problems in Flexible Manufacturing System Using Variable Neighborhood Search," IAENG International Journal of Computer Science, vol. 42, no. 3, 2015.

[7] D. Novitasari, I. Cholissodin, and W. F. Mahmudy, "Hybridizing PSO with SA for optimizing SVR applied to software effort estimation," TELKOMNIKA (Telecommunication Computing Electronics and Control), vol. 14, no. 1, pp. 245-253, 2016.

[8] H. Shahinzadeh, S. M. Nasr-azadani, and N. Jannesari, "Applications of Particle Swarm Optimization Algorithm to Solving the Economic Load Dispatch of Units in Power Systems with Valve-Point Effects," International Journal of Electrical and Computer Engineering (IJECE), vol. 4, no. 6, pp. 858-867, 2014.

[9] Y. J. Gong et al., "Genetic Learning Particle Swarm Optimization," IEEE Transactions on Cybernetics, pp. 1-14, 2015.

[10] X. Yan, Q. Wu, and H. Liu, "Orthogoal Particle Swarm Optimization Algorithm and Its Application in Circuit Design," TELKOMNIKA (Telecommunication Computing Electronics and Control), vol. 11, no. 6, pp. 2926-2932, 2013.

[11] B. X. Liu, Y. Wu, X. Xu, N. Hu, and X. Cheng, "Chaos Adaptive Improved Particle Swarm Algorithm for Solving Multi-Objective Optimization,” TELKOMNIKA (Telecommunication Computing Electronics and Control), vol. 12, no. 1, pp. 703-710, 2014.

[12] M. C. C. Utomo, W. F. Mahmudy, and S. Anam, "Determining the Neuron Weights of Fuzzy Neural Networks Using Multi-Populations Particle Swarm Optimization for Rainfall Forecasting," Journal of Telecommunication, Electronic and Computer Engineering, vol. 9, no. 2, pp. 37-42, 2017.

[13] A. A. Altun and M. A. Şahman, "Cost optimization of mixed feeds with the particle swarm optimization method," Neural Computing and Applications, vol. 22, no. 2, pp. 383-390, 2011.

[14] D. Xu, "Multi-objective Optimization Model of Nutritional Ingredients for Poultry Based on Particle Swarm Optimization Algorithm," Technical Journal of the Faculty of Engineering, vol. 39, pp. 286-293, 2016.

[15] F. Van Den Bergh and A. P. Engelbrecht, "A study of particle swarm optimization particle trajectories," Information Sciences, vol. 176, no. 8, pp. 937-971, 2006.

[16] J. Kennedy and R. Eberhart, "Particle swarm optimization," Neural Networks, 1995. Proceedings., IEEE International Conference on, vol. 4, pp. 1942-1948 vol.4, 1995.

[17] Y. Shi and R. Eberhart, "A modified particle swarm optimizer," Evolutionary Computation Proceedings, 1998. IEEE World Congress on Computational Intelligence., The 1998 IEEE International Conference on, pp. 69-73, 1998.

[18] T. Weise, Global Optimization Algorithms - Theory and Application. 2009.

[19] S. N. Indonesia and B. S. Nasional, "Laying Hen Feed - Part 1 (Layer Pre Starter) (Pakan ayam ras petelur - Bagian 1 : Sebelum masa awal ( Layer pre starter))," 2016.

[20] S. N. Indonesia and B. S. Nasional, "Laying Hen Feed - Part 2 (Layer Starter) (Pakan ayam ras petelur - Bagian 2 : masa awal ( starter ))," 2016. 
[21] S. N. Indonesia and B. S. Nasional, "Laying Hen Feed - Part 3 (Layer Grower) (Pakan ayam ras petelur ( layer ) Bagian 3: Layer Grower)," 2016.

[22] S. N. Indonesia and B. S. Nasional, "Laying Hen Feed - Part 4 (Pre Layer) (Pakan ayam ras petelur - Bagian 4 : Sebelum produksi ( Pre layer ))," 2016.

[23] S. N. Indonesia and B. S. Nasional, "Laying Hen Feed (Layer) Part 5 : Production Period (Pakan ayam ras petelur ( layer ) Bagian 5: Masa produksi)," 2016.

[24] S. N. Indonesia and B. S. Nasional, "Laying Hen Feed Part 6: Post Production Period (Pakan ayam ras petelur Bagian 6 : Setelah puncak produksi)," 2016.

[25] A. Rezaee Jordehi and J. Jasni, "Parameter selection in particle swarm optimisation: a survey," Journal of Experimental \& Theoretical Artificial Intelligence, vol. 25, no. 4, pp. 527-542, 2013.

[26] Y. S. R.C. Eberhart, "Comparing nonlinear inertia weights and constriction factors in particle swarm optimization," Proc. CEC, San Diego, CA, vol. 15, no. 2, pp. 65-70, 2000.

\section{BIOGRAPHIES OF AUTHORS}

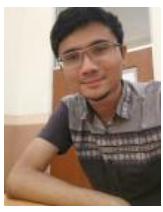

Gusti Ahmad Fanshuri Alfarisy is now pursuing his master's degree at the Computer Science Faculty in Universitas Brawijaya. His current research interests focus on the swarm intelligence, animal diet formulation optimization, and web intelligence.

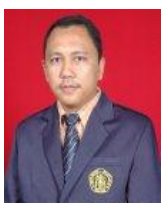

Wayan Firdaus Mahmudy is a Dean of Faculty of Computer Science at Brawijaya University. He is a research supervision of Intelegent System Research Group Faculty of Computer Science at Brawijaya University. He also as a lecturer at master's degree in Faculty of Computer Science at Brawijaya University.

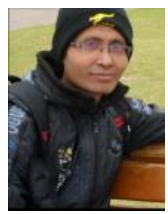

Muhammad Halim Natsir is a lecturer at the Faculty of Animal Husbandry, Universitas Brawijaya, Indonesia. He was awarded a doctorate in Nutrition and Feed Science at the Faculty of Animal Husbandry, Universitas Brawijaya, Indonesia.

APPENDIX

Feed Ingredients:

\begin{tabular}{llllllllllll}
\hline Index & Ingredients & $\begin{array}{l}\text { Price in } \\
\text { Rupiah }\end{array}$ & ME & CP & $\begin{array}{l}\text { Crude } \\
\text { Fat }\end{array}$ & CF & Ca & P & Na & K & Cl \\
\hline 0 & Bran & 2500 & 1630 & 8 & 8 & 12 & 0.12 & 0.21 & 0.07 & 1.7 & 0.07 \\
1 & Corn Bran & 4000 & 2950 & 10.6 & 6 & 5 & 0.04 & 0.15 & 0.06 & 1.2 & 0.07 \\
2 & Wheat & 20000 & 2980 & 10.7 & 2.1 & 2.1 & 0.05 & 0 & 0 & 0 & 0 \\
3 & Yellow Corn & 5000 & 3370 & 8.54 & 2.61 & 4.76 & 0.02 & 0.1 & 0.02 & 0.28 & 0.04 \\
4 & Menir & 6000 & 3390 & 8.9 & 4 & 3 & 0.03 & 0.4 & 0 & 0 & 0 \\
5 & Pollard & 2300 & 1300 & 15 & 4 & 10 & 0.14 & 0.32 & 1.2 & 1.1 & 0.09 \\
6 & Sorghum & 6000 & 3250 & 10 & 2.8 & 2 & 0.03 & 0.1 & 0.01 & 0.35 & 0.08 \\
7 & Cotton Seed Meal & 2500 & 2100 & 41 & 4.8 & 12 & 0.18 & 0.33 & 0.03 & 1.2 & 0.05 \\
8 & Rubber Seed Meal & 4500 & 2159 & 24.2 & 3.45 & 9.8 & 0.11 & 0 & 0 & 0 & 0 \\
9 & Soybean Meal & 3000 & 2240 & 42 & 0.9 & 6 & 0.29 & 0.65 & 0.03 & 1.2 & 0.03 \\
10 & Coconut Meal & 3500 & 2200 & 18.5 & 2.5 & 15 & 0.2 & 0.57 & 0.04 & 1.1 & 0.03 \\
11 & Peanut Meal & 3000 & 2200 & 42 & 1.9 & 17 & 0.2 & 0.2 & 0.07 & 1.2 & 0.03 \\
12 & Foka & 2000 & 2700 & 14 & 1.8 & 10.1 & 2.25 & 1 & 0.1 & 1.1 & 0.07 \\
13 & Hidrolisis I. Rumen & 2500 & 2000 & 16.2 & 2.3 & 25.4 & 0.38 & 0.55 & 0 & 0 & 0 \\
14 & MBM & 5000 & 2190 & 52 & 10 & 2.8 & 10 & 5.1 & 0.7 & 1.45 & 0.69 \\
15 & Skim Milk & 30000 & 2510 & 33 & 0.9 & 0.2 & 1.3 & 1 & 0.5 & 1.5 & 0.9 \\
\hline
\end{tabular}




\begin{tabular}{|c|c|c|c|c|c|c|c|c|c|c|c|}
\hline Index & Ingredients & $\begin{array}{l}\text { Price in } \\
\text { Rupiah }\end{array}$ & $\mathrm{ME}$ & $\mathrm{CP}$ & $\begin{array}{l}\text { Crude } \\
\text { Fat }\end{array}$ & $\mathrm{CF}$ & $\mathrm{Ca}$ & $\mathrm{P}$ & $\mathrm{Na}$ & $\mathrm{K}$ & $\mathrm{Cl}$ \\
\hline 16 & $\begin{array}{l}\text { Fish Flour } \\
\text { (Ancovetta) }\end{array}$ & 7500 & 2830 & 65 & 4 & 1 & 4 & 2.6 & 0.8 & 0.7 & 0.3 \\
\hline 17 & Fish Flour (Herring) & 8000 & 2640 & 72 & 10 & 1 & 2 & 1.5 & 0.5 & 1.1 & 1 \\
\hline 18 & $\begin{array}{l}\text { Fish Flour } \\
\text { (Menhaden) }\end{array}$ & 8500 & 2650 & 54 & 9 & 1 & 5.5 & 2.8 & 0.3 & 0.7 & 1.2 \\
\hline 19 & Snail Flour & 6500 & 4906 & 61 & 6.1 & 4.5 & 2 & 0 & 0 & 0 & 0 \\
\hline 20 & Quill Flour & 5000 & 2310 & 85 & 2.5 & 1.5 & 0.32 & 0.32 & 0 & 0 & 0 \\
\hline 21 & Meat Flour & 5000 & 2957 & 57 & 12 & 0 & 5.96 & 0 & 0 & 0 & 0 \\
\hline 22 & Blood Flour & 5000 & 2750 & 85 & 1.1 & 1 & 0.15 & 0.32 & 0.32 & 0.09 & 0.27 \\
\hline 23 & Lamtoro Flour & 4500 & 828 & 18.9 & 5.9 & 16.3 & 0.05 & 0 & 0 & 0 & 0 \\
\hline 24 & Chalk & 1100 & 0 & 0 & 0 & 0 & 38 & 0 & 0 & 0 & 0 \\
\hline 25 & Clamshell & 6000 & 0 & 0 & 0 & 0 & 37 & 0 & 0 & 0 & 0 \\
\hline 26 & Bone Flour & 6000 & 818 & 12 & 3 & 2.3 & 26 & 13.5 & 0 & 0 & 0 \\
\hline 27 & Fish Oil & 150000 & 8450 & 0 & 100 & 0 & 0 & 0 & 0 & 0 & 0 \\
\hline 28 & Coconut Oil & 11500 & 8600 & 0 & 100 & 0 & 0 & 0 & 0 & 0 & 0 \\
\hline 29 & Plant Oil & 12000 & 8950 & 0 & 100 & 0 & 0 & 0 & 0 & 0 & 0 \\
\hline 30 & Cassava Flour & 2400 & 2970 & 1.5 & 0.7 & 0.9 & 0.18 & 0.09 & 0.06 & 0.01 & 0.07 \\
\hline
\end{tabular}

\begin{tabular}{|c|c|c|c|c|c|c|c|c|c|c|c|}
\hline Index & Ingredients & $\mathrm{Mn}$ & $\mathrm{Zn}$ & Arg & Cys & Gly & His & Isol & Leu & Lis & Met \\
\hline 0 & Bran & 200 & 30 & 1.4 & 0.4 & 0.8 & 0.56 & 0.61 & 1.2 & 0.77 & 0.29 \\
\hline 1 & Corn Bran & 115 & 80 & 0.8 & 0.2 & 0.9 & 0.3 & 0.6 & 0.9 & 0.5 & 0.17 \\
\hline 2 & Wheat & 0 & 0 & 0 & 0 & 0 & 0 & 0 & 0 & 0 & 0.31 \\
\hline 3 & Yellow Corn & 5 & 10 & 0.5 & 0.18 & 0.4 & 0.2 & 0.4 & 0.1 & 0.2 & 0.18 \\
\hline 4 & Menir & 0 & 0 & 0.36 & 0 & 0 & 0 & 0 & 0 & 0 & 0.27 \\
\hline 5 & Pollard & 18 & 15 & 0.7 & 0.1 & 0.8 & 0.18 & 0.38 & 0.6 & 0.3 & 0.17 \\
\hline 6 & Sorghum & 13 & 17 & 0.36 & 0.15 & 0.4 & 0.19 & 0.46 & 1.4 & 0.2 & 0.13 \\
\hline 7 & Cotton Seed Meal & 23 & 0 & 4.4 & 1 & 2.4 & 1.1 & 1.6 & 2.4 & 1.6 & 0.6 \\
\hline 8 & Rubber Seed Meal & 0 & 0 & 0 & 0 & 0 & 0 & 0 & 0 & 0 & 0 \\
\hline 9 & Soybean Meal & 35 & 27 & 3.2 & 0.67 & 2.1 & 1.1 & 2.5 & 3.4 & 2.9 & 0.65 \\
\hline 10 & Coconut Meal & 55 & 100 & 2.7 & 0.3 & 1 & 0.56 & 0.66 & 1.49 & 0.64 & 0.29 \\
\hline 11 & Peanut Meal & 29 & 20 & 5.2 & 0.8 & 2.6 & 1.1 & 2.2 & 3.2 & 1.8 & 0.5 \\
\hline 12 & Foka & 0 & 0 & 0.013 & 0.37 & 0.2 & 0.52 & 0.56 & 1.4 & 0.71 & 0.27 \\
\hline 13 & Hidrolisis I. Rumen & 0 & 0 & 0 & 0 & 0 & 0 & 0 & 0 & 0 & 0 \\
\hline 14 & MBM & 14 & 93 & 3.28 & 0.69 & 6.65 & 0.96 & 1.54 & 3.28 & 2.61 & 0.69 \\
\hline 15 & Skim Milk & 2 & 40 & 1.1 & 0.42 & 0.7 & 0.84 & 2.1 & 3.3 & 2.3 & 1 \\
\hline 16 & $\begin{array}{l}\text { Fish Flour } \\
\text { (Ancovetta) }\end{array}$ & 22 & 110 & 3.4 & 1 & 4.6 & 1.5 & 3.6 & 5 & 5.2 & 1.8 \\
\hline 17 & Fish Flour (Herring) & 10 & & 6.8 & 1.2 & 5.9 & 1.6 & 3.7 & 5.19 & 6.4 & 2 \\
\hline 18 & $\begin{array}{l}\text { Fish Flour } \\
\text { (Menhaden) }\end{array}$ & 36 & 150 & 3.8 & 0.94 & 4.4 & 1.4 & 3.6 & 5 & 4 & 1.3 \\
\hline 19 & Snail Flour & 0 & 0 & 0 & 0 & 0 & 0 & 0 & 0 & 0 & 4.35 \\
\hline 20 & Quill Flour & 0 & 0 & 5.6 & 3 & 0 & 0 & 0 & 0 & 1.5 & 0.5 \\
\hline 21 & Meat Flour & 0 & 0 & 0 & 0 & 0 & 0 & 0 & 0 & 0 & 3.31 \\
\hline 22 & Blood Flour & 5 & 0 & 3.5 & 1.4 & 3.4 & 4.2 & 1 & 10.2 & 6.9 & 6.9 \\
\hline 23 & Lamtoro Flour & 0 & 0 & 0 & 0 & 0 & 0 & 0 & 0 & 0 & 0.55 \\
\hline 24 & Chalk & 0 & 0 & 0 & 0 & 0 & 0 & 0 & 0 & 0 & 0 \\
\hline 25 & Clamshell & 0 & 0 & 0 & 0 & 0 & 0 & 0 & 0 & 0 & 0 \\
\hline 26 & Bone Flour & 0 & 0 & 0 & 0 & 0 & 0 & 0 & 0 & 0 & 1.27 \\
\hline 27 & Fish Oil & 0 & 0 & 0 & 0 & 0 & 0 & 0 & 0 & 0 & 0 \\
\hline
\end{tabular}




\begin{tabular}{llllllllllll}
\hline Index & Ingredients & Mn & Zn & Arg & Cys & Gly & His & Isol & Leu & Lis & Met \\
\hline 28 & Coconut Oil & 0 & 0 & 0 & 0 & 0 & 0 & 0 & 0 & 0 & 0 \\
29 & Plant Oil & 0 & 0 & 0 & 0 & 0 & 0 & 0 & 0 & 0 & 0 \\
30 & Cassava Flour & 115 & 90 & 0.04 & 0.1 & 0.1 & 0.15 & 0.3 & 0.45 & 0.03 & 0.09 \\
\hline
\end{tabular}

